\title{
Migración irregular extracontinental en México. Apuntes para el diseño de una política y gestión migratoria
}

\author{
JUAN CARLOS NARVÁEZ GUTIÉRREZ*
}

RESUMEN: En el presente artículo se pretende responder a tres preguntas centrales: qué es la migración extracontinental, quiénes son los migrantes que componen este flujo migratorio y qué hace México para atender este fenómeno. Para ello se analizan los principales flujos de migrantes extracontinentales procedentes de África y Asia que se internan de manera irregular en México; algunas de sus características sociodemográficas, rutas y estrategias migratorias; así como algunos de los retos que impone este flujo a la gestión migratoria. A manera de cierre se presentan algunas posibles líneas de acción para el diseño de política migratoria. La propuesta se basa en información estadística de los registros administrativos sobre migrantes que son alojados en las estaciones migratorias del Instituto Nacional de Migración (INM), así como fuentes de información complementarias.

PALABRAS CLAVE: migración irregular de tránsito, migración irregular extracontinental, Conferencia Regional sobre Migración (CRM), política migratoria, México.

* Centro de Estudios Migratorios. Unidad de Política Migratoria, México. 
ABSTRACT: This article intends to answer three central questions: What is extra-continental migration? Who are the migrants that make up this migratory flow? and, What is Mexico doing to address this phenomenon? To that end, we analyze the key extra-continental migratory flows originating in Africa and Asia that are directed toward Mexico; certain socio-demographic characteristics, routes and migratory strategies; as well as some of the challenges that this flow represents to the management of migration. Concluding the article, we present some possible lines of action for the design of migratory policy. These proposals are based on statistical information from administrative registries on migrants maintained by the National Migration Institute (INM) as well as complementary information sources.

KEY WORDS: irregular transit migration, irregular extra-continental migration, Regional Migration Conference (CRM), migratory policy, Mexico. 


\section{INTRODUCCIÓN ${ }^{1}$}

Y

a no resulta nuevo hablar de México como un país que posee más de una dimensión migratoria - emigración, inmigración, tránsito o retorno migratorio-, sin embargo, es relativamente reciente que, cada vez más, en el discurso académico, político e incluso en los medios de comunicación se comparta la preocupación sobre la política y la gestión migratoria en México; particularmente es relevante entender cómo tendrían que atenderse de manera integral las causas y los efectos de las migraciones.

Sobre la larga tradición emigratoria de mexicanos hacia Estados Unidos y en menor medida hacia Canadá, en la actualidad se cuenta con un cúmulo de conocimiento y experiencias que han sido útiles para el diseño de medidas y programas de atención. No obstante, con respecto a la producción de investigaciones sobre otras dimensiones del fenómeno en México, aún existe una deuda pendiente.

Es cierto que en los últimos 10 años ha adquirido importancia el estudio y la investigación sobre la inmigración, el tránsito irregular y el retorno en México, además de temas transversales como la migración y los derechos humanos, la violencia, el desarrollo y actores emergentes como migrantes menores de edad, e incluso se puede afirmar que son líneas de investigación en proceso de consolidación que han aportado importantes resultados a la política pública (Casillas, 2008; Rodríguez, 2010; Rodríguez et al., 2010, 2012).

Dada la dinámica global del fenómeno migratorio, permanentemente emergen nuevos temas, enfoques y actores en este contexto, un caso particular resulta el de la migración extracontinental irregular en México. En

1 Una versión preliminar de este trabajo se presentó en el marco del «Taller sobre flujos migratorios extracontinentales» de la Comisión Especial de Asuntos Migratorios de la Organización de Estados Americanos (OEA), el 8 de mayo de 2012 en Washington. Se agradece a Ernesto Rodríguez Chávez por los valiosos comentarios y aportes al trabajo que antecede a este documento; a Nina Frías Valle, quien colaboró en las versiones previas; a Edna T. Guzmán, por su lectura crítica; y a Salvador Cobo. Las opiniones aquí vertidas no necesariamente corresponden a la institución de adscripción del autor. 
este texto se pretende responder a tres preguntas centrales: qué es la migración extracontinental, quiénes son los migrantes que la componen y qué hace México para atender este fenómeno. Para ello, se analizan los principales flujos de migrantes extracontinentales procedentes de África y Asia que se internan de manera irregular en México, algunas de las características sociodemográficas, las rutas y estrategias migratorias, y algunos de los retos que impone este flujo a la gestión migratoria. Finalmente, a manera de cierre se presentan algunas posibles líneas de acción para el diseño de política migratoria. La propuesta se basa en información estadística de los registros administrativos sobre migrantes que son alojados en las estaciones migratorias del Instituto Nacional de Migración (INM), así como fuentes de información complementarias.

\section{¿QUÉ ES LA MigRACIÓN EXTRACONTINENTAL?}

Actualmente son pocos los estudios de largo alcance en América Latina² que abordan el fenómeno de las migraciones irregulares de origen extracontinental. De acuerdo con uno de los trabajos más relevantes, se definen como aquellos «flujos mixtos compuestos por migrantes económicos y, en menor medida, por personas refugiadas, solicitantes de asilo y otras categorías de personas, entre los cuales también se identifica a víctimas de trata de personas y tráfico ilícito de migrantes, provenientes de algunos países específicos de África y Asia» (Flacso, 2011: 5), entre los cuales destacan los procedentes de las naciones africanas de Eritrea, Etiopia, Nigeria y Somalia, y de las naciones asiáticas de China, Bangladesh, India, Sri Lanka y Nepal (OEA, 2010).

Aunque la migración extracontinental no representa aún un flujo de gran magnitud o volumen, se trata de un fenómeno complejo en cuanto a

\footnotetext{
2 Uno de los trabajos más detallados sobre el fenómeno es el elaborado por la Facultad Latinoamericana de Ciencias Sociales (Flacso, 2011) a solicitud de los gobiernos que conforman la Conferencia Regional sobre Migración (CRM), dicho estudio dota de algunos elementos que permiten conocer un poco más sobre estos flujos irregulares migratorios y construir, a partir de esto, algunas definiciones, así como preguntas de investigación que abonen elementos para la política migratoria.
}

$120 \frac{\text { PRIMER SEMESTRE } 2015}{\text { MIGRACIÓN Y DESARROLLO NÚM. } 24}$ 
su atención desde la política y gestión migratoria, ya que, por un lado, se está frente a una gran diversidad étnica y distanciamiento geográfico, cultural e idiomático derivada de los orígenes continentales -África/Asia-, $y$, por otro lado, se presenta la condición de irregularidad en la que se internan o desplazan las personas que componen este flujo por los territorios de tránsito migratorio - el continente americano- colocándolos como potenciales víctimas de tráfico, trata y otros riesgos intrínsecos a la movilidad irregular. ${ }^{3}$

Las motivaciones de esta migración hacia el continente americano son diversas, sin embargo, destacan en este tipo de flujos migratorios la persecución social, cultural, política y religiosa; los conflictos armados; las violaciones masivas y permanentes de los derechos humanos; y otras clases de riesgos que vulneran y ponen en peligro la vida de las personas en sus lugares de origen, además de las razones económicas.

En este sentido, se trata de un fenómeno de alcance global e impacto regional que se enmarca en el plano de la corresponsabilidad (coordinación o cooperación) migratoria entre los países de origen, destino y tránsito, que además adquiere particularidades en cuanto a la política y gestión migratoria para cada uno de los países por los que atraviesa este flujo de migrantes, las cuales se asocian, principalmente, al contexto político, social y económico del país de tránsito como del país del cual proviene el migrante.

Dicho esto, en el caso de México sería imposible desmarcar el análisis de esta migración extracontinental del flujo migratorio centroamericano de tránsito irregular que se desplaza por territorio nacional para llegar a Estados Unidos o Canadá, ya que comparten, entre otros factores, la condición de irregularidad — con toda la carga de vulnerabilidad social que ello implicay un destino migratorio compartido (Rodríguez, 2010: 32).

${ }^{3}$ En abril de 2010, la Organización de Estados Americanos (OEA), a través de la Comisión Especial de Asuntos Migratorios, convocó a representantes de los Estados miembros a un taller en la ciudad de Washington para analizar y compartir información sobre la reciente llegada al continente americano de flujos de migrantes irregulares procedentes de África y en menor medida de Asia. Dicho taller se enmarcó dentro las acciones que lleva a cabo el Programa de Migración y Desarrollo de la OEA, que a solicitud del secretario general puso en la agenda un tema de preocupación regional (OEA, 2010). 


\section{¿QUiÉNES SON LOS MIGRANTES IRREGULARES extracontinentales en MÉxico?}

De acuerdo con algunos hallazgos de la Organización Internacional para las Migraciones (OIM), la mayoría de los migrantes extracontinentales, tanto los procedentes de África como de Asia, se internan en el continente americano por vía aérea o marítima de manera regular, por lo general utilizando países que no solicitan visa como puerto de entrada, presentando algún documento de viaje en los países de arribo o plataforma (se trata principalmente de países que no exigen visado a algunos países de África o Asia, o bien a los que estos migrantes pueden arribar solicitando asilo).

En este sentido, un migrante en tránsito de origen extracontinental puede ingresar a México de manera regular, y una vez dentro del territorio -al dejar vencer sus visas o permisos de estancia temporal y permanecer en el territorio-, pasar a una condición de irregularidad por el carácter de overstayer, o bien, desde su ingreso al país por tierra o mar sin presentar documentos migratorios válidos y vigentes, se convierten en migrantes de tránsito irregular (Scott, 2010: 13).

En el contexto latinoamericano, por lo general, la irregularidad de los migrantes extracontinentales inicia realmente en el momento en que deciden continuar su ruta hacia Norteamérica, ingresando y atravesando por los países de la región sin documentación migratoria o solicitando de manera recurrente en cada uno de estos países el refugio.

Aunque se ha visto que el problema de lo público que genera este flujo migratorio de tránsito irregular impacta a más de un país de la región, como Colombia, Panamá, Costa Rica, El Salvador o Guatemala, en el contexto actual de México, visibilizar y ocuparse de este fenómeno resulta relevante, ya que el país - por su posición geográfica de vecindad al norte con Estados Unidos y al sur con Centroamérica - se impone como ruta obligada para estos migrantes y para los miles de migrantes centroamericanos que anualmente tratan de llegar a Estados Unidos atravesando de manera irregular el territorio mexicano (Flacso, 2011; OIM, 2013).

$122 \frac{\text { PRIMER SEMESTRE } 2015}{\text { MIGRACIÓN Y DESARROLLO NÚM. } 24}$ 
El flujo migratorio histórico que se interna y transita de forma irregular por México se compone en su mayoría (94 por ciento) de migrantes procedentes de Centroamérica (Guatemala, El Salvador y Honduras). Aunque en los últimos años la participación del flujo de migrantes extracontinentales no ha superado 5 por ciento 4 de los eventos de migración irregular, es necesario saber más del fenómeno migratorio extracontinental para detectar y atender sus necesidades desde la política y gestión migratoria.

Durante 2013, el número de africanos y asiáticos presentados ${ }^{5}$ ante el Instituto Nacional de Migración (INM) no sobrepasó 2 por ciento de los eventos de extranjeros irregulares, sin embargo, su incorporación a estos flujos migratorios llamó la atención de los sectores gubernamental y académico en 2010 al observarse un repunte inesperado que representó alrededor de 4 por ciento de los eventos de migrantes alojados en una estación migratoria del INM (véase gráfica 1).

\section{GRÁFICA 1}

Eventos de extranjeros presentados (alojados) ante la autoridad migratoria, 2013

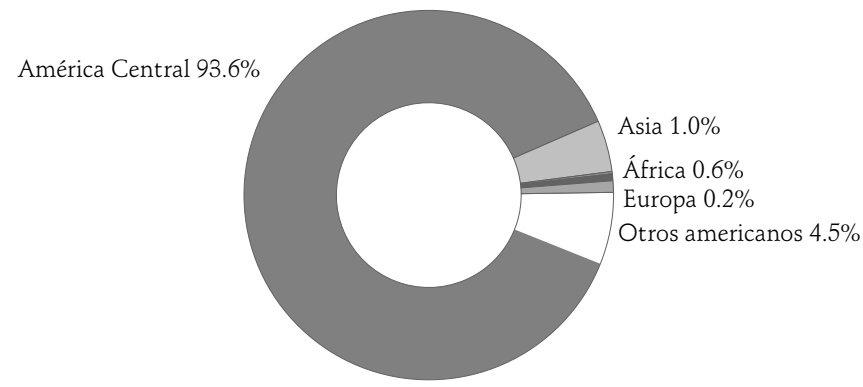

Fuente: Elaboración con base en el Boletín de Estadística del Centro de Estudios Migratorios de la Unidad de Política Migratoria. http://www.politicamigratoria.gob.mx/es_mx/SEGOB/Boletines_Estadisticos

${ }^{4}$ En 2010, año en que registró este flujo una mayor participación, representaron alrededor de 2,300 eventos.

${ }^{5}$ El proceso de aseguramiento que se sigue con los nacionales de África y Asia es el mismo que se sigue con los demás extranjeros (en su mayoría originarios de Centroamérica) que no pueden comprobar legal estancia en el territorio nacional. Los extranjeros son alojados en las estaciones migratorias en donde se les brinda alimentación y dormitorio, así como todas las garantías de Ley. 
Con base en estos registros se puede observar, en una línea de tiempo (véase gráfica 2), que el comportamiento de estos flujos por México coincide con las tendencias que registran otras migraciones en tránsito irregular por el país. ${ }^{6}$ En 2005, cuando también se registró el máximo histórico de eventos de migrantes irregulares procedentes de Centroamérica transitando por México, se observa un repunte en el flujo de los migrantes procedentes de África y de Asia.

Dicho incremento se expresa y se hace visible en 2010 cuando ambos flujos (africanos y asiáticos) alcanzan un máximo de 1,282 eventos los primeros y 1,049 los segundos. Sin embargo, en 2011 se presenta una reducción de los eventos descendiendo a 287 y 831 , respectivamente, tendencia que comienza a revertirse en 2013, ascendiendo a 545 y 894 eventos procedentes de África y Asia.

\section{GRÁFICA 2}

Eventos de extranjeros procedentes de África y Asia presentados (alojados) en estaciones migratorias de 1995 a 2013

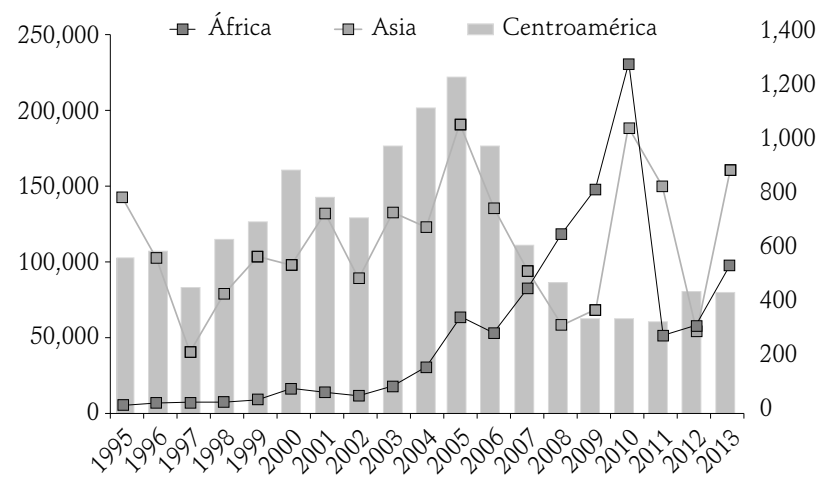

Fuente: Elaboración con base en el Boletín de Estadística Migratoria del Centro de Estudios Migratorios de la Unidad de Política Migratoria. http://www.politicamigratoria.gob.mx/es_mx/SEGOB/Boletines_Estadisticos

${ }^{6}$ Es importante señalar que dichos cálculos son producto de una estimación indirecta - a partir de los registros de eventos de extranjeros retenidos por la autoridad migratoria y alojados en las estaciones migratorias del INM - del volumen de migrantes africanos y asiáticos que ingresan y transitan de manera irregular por territorio mexicano, por lo tanto se limita a los migrantes que de manera voluntaria o no voluntaria fueron registrados por este proceso administrativo.

$124 \frac{\text { PRIMER SEMESTRE } 2015}{\text { MIGRACIÓN Y DESARROLLO NÚM. } 24}$ 
En cuanto a la distribución por nacionalidad de la población migrante extracontinental alojada en las estaciones migratorias del INM durante 2013, de acuerdo con los datos de la gráfica 3, el 67.2 por ciento de los alojados procedentes de Asia corresponde a los nacionales de India, seguidos, aunque de manera muy distante, de China (11.3 por ciento), Bangladesh (9.4 por ciento), Nepal (4.5 por ciento) y otros. Respecto a las nacionalidades más frecuentes procedentes de África, 62.2 por ciento corresponde a Somalia, 12.7 por ciento a Eritrea, 11.9 por ciento a Ghana y el resto a Etiopia, Nigeria y a otros países del continente.

\section{GRÁFICA 3}

Eventos de extranjeros asiáticos y africanos presentados (alojados) ante la autoridad migratoria, 2013

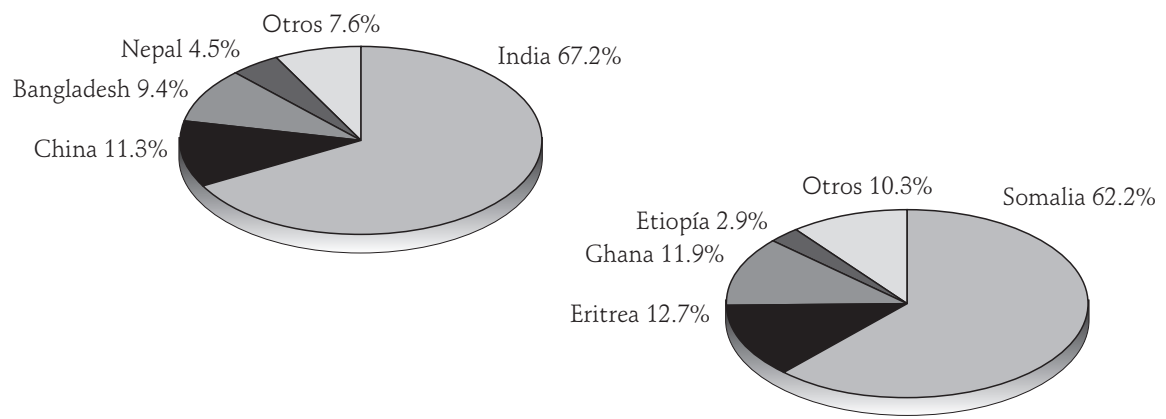

Fuente: Elaboración con base en el Boletín de Estadística Migratoria del Centro de Estudios Migratorios de la Unidad de Política Migratoria. http://www.politicamigratoria.gob.mx/es_mx/SEGOB/Boletines_Estadisticos.

Ambos flujos comparten un patrón en cuanto a las características sociodemográficas generales, es decir, se trata en su mayoría de migrantes hombres ( 89 por ciento), solteros (87 por ciento), con instrucción y educación básica (63 por ciento) y con manejo de un segundo idioma (73 por ciento); en el cuadro 1 se muestran algunas diferencias entre variables que podrían ser significativas y potencialmente útiles a lo largo de las trayectorias migratorias e incorporación de ambas poblaciones: escolaridad y manejo de idioma. 


\section{CUADRO 1}

Características seleccionadas de la población migrante extracontinental irregular en México, según continente del país de nacionalidad, 2012 (proporciones)

\begin{tabular}{lrrr}
\hline \multicolumn{1}{c}{ CARACTERÍSTICAS SELECCIONADAS } & \multicolumn{2}{c}{ CONTINENTE } & \\
\cline { 2 - 3 } & ASIA & ÁFrICA & TOTAL \\
\hline $\begin{array}{l}\text { Sexo } \\
\text { Proporción de hombres }\end{array}$ & 86 & 91 & 89 \\
$\begin{array}{l}\text { Edad } \\
\text { Mediana }\end{array}$ & 28 & 27 & 28 \\
Escolaridad & 22 & 7 & 14 \\
Proporción sin instrucción & 48 & 77 & 63 \\
Proporción con educación básica & & & \\
Estado civil & 83 & 91 & 87 \\
Proporción de solteros & 25 & 62 & 45 \\
Idioma & 19 & 36 & 28 \\
Proporción que habla inglés & 286 & 318 & 604 \\
Proporción que habla español & & & \\
N & & & \\
\hline
\end{tabular}

Fuente: Elaboración propia con base en los registros administrativos del Instituto Nacional de Migración, relacionados con personas presentadas por no acreditar legal estancia en México. Información preliminar. Nota: La información es un ejercicio que pretende dibujar, de manera indicativa, los posibles perfiles sociodemográficos de los migrantes extracontinentales en su tránsito por México. El número de casos por continente no corresponde necesariamente al total de migrantes extracontinentales mostrados en este documento, debido a la no disponibilidad de la información en bases de datos (microdatos). El Centro de Estudios Migratorios de la Unidad de Política Migratoria, a través del área de estadística, trabaja desde hace un par de años en la revisión y en la mejora continua de la información reportada por las delegaciones regionales, oficinas de trámite y estaciones y/o estancias migratorias del Instituto Nacional de Migración.

Entre los migrantes extracontinentales que ingresan de manera irregular, algunos que proceden de países donde la vida se encuentra en riesgo, solicitan la condición de refugiados desde las estaciones migratorias y son canalizados a las oficinas de la Comisión Mexicana de Ayuda a Refugiados para iniciar los trámites.

Si no se les reconoce la condición como refugiados, y no puede ser efectuado el proceso de repatriación a su país de origen debido a que no cuentan con las condiciones necesarias para su retorno como la ausencia de representación diplomática o consular, no hay reconocimiento del extranjero por

$126 \frac{\text { PRIMER SEMESTRE } 2015}{\text { MIGRACIÓN Y DESARROLLO NÚM. } 24}$ 
parte de su gobierno porque sobrepasan los 60 días permitidos por la Ley de Migración para permanecer en las estaciones migratorias — por ejemplo, los nacionales de Etiopia no pueden ser retornados a su país por falta de un salvoconducto de viaje para la repatriación-, se les otorga un oficio de salida, ya sea para que dejen el país o bien regularicen su situación migratoria en México.

En los últimos años, de acuerdo con los registros administrativos del INM, del total de eventos de migración extracontinental procedentes de Asia en promedio son repatriados 13 por ciento, y de los procedentes de África 3 por ciento, el resto sale por sus propios medios del país; regularizan su situación, siguen el camino hacia Estados Unidos o bien permanecen en México de manera irregular. Lo anterior, aunque es indicativo y no hay suficiente evidencia empírica para profundizar, habla de la complejidad que representa este flujo para la gestión migratoria.

\section{¿Qué hace México para atender este flujo migratorio DESDE LA POLÍTICA Y GESTIÓN MIGRATORIA?}

El incremento sustancial de los flujos migratorios irregulares procedentes de Asia y África, experimentado en México en los últimos años - puntualmente en 2010 - visibilizó las dificultades institucionales que impone el tratamiento de este flujo para el gobierno de México y los de la región. Dado que, por un lado, se trata de un flujo migratorio en tránsito irregular que tiene como objetivo final llegar a Estados Unidos o Canadá — dimensión del fenómeno que en sí misma es contenedora de diferentes problemáticas públicas-, y, por otro, muchos de estos migrantes proceden de países en conflicto, por lo que los gobiernos, para su atención, se rigen en las directrices que señala el Alto Comisionado de las Naciones Unidas para los Refugiados (ACNUR).

El gobierno de México, con base en lo anterior, les informa a los migrantes extracontinentales las vías y posibilidades que tienen para regularizar su estancia, así como también se les informa acerca de la posibilidad de presentar 
una solicitud para ser reconocidos como refugiados e incluso de recibir protección complementaria. Sin embargo, no todos los migrantes están dispuestos o reúnen el perfil para poder acogerse a alguna de estas medidas, ya sea porque su plan es continuar hacia Estados Unidos en el menor tiempo posible o no buscan en México un destino migratorio (temporal o permanente).

En cuanto a la gestión de los flujos migratorios extracontinentales, el Estado mexicano se enfrenta a más de un obstáculo tanto de orden institucional como de cooperación y coordinación internacional. Además de otros factores que dificultan una buena gestión migratoria, como la diversidad de idiomas, ${ }^{7}$ las particularidades alimenticias, religiosas y culturales de los migrantes que también son elementos relevantes que requieren atención inmediata.

De acuerdo con la normatividad nacional y otras de carácter internacional (Ley de Migración, Ley General de Población y Ley sobre Refugiados y Protección Complementaria), el Estado mexicano, frente a los flujos de migrantes irregulares procedentes de Asia y África, ha procurado distintas alternativas para brindar atención a los migrantes extracontinentales. ${ }^{8}$

Entre las acciones gubernamentales que se han propuesto por parte de las distintas instituciones que gestionan la migración irregular en México se cuentan protocolos específicos para población en situación de vulnerabilidad; atención y seguimiento a los solicitantes de reconocimiento como refugiados o de protección complementaria; la incorporación de la población de origen extracontinental al Programa de Retornos Voluntarios Asistidos; en casos particulares se invita al migrante irregular y extracontinental a

7 Entre los idiomas que se han documentado en los registros administrativos se encuentran el alemán, árabe, bengalí, chino, coreano, español, francés, hindi, indonesio, inglés, mandarín y variantes, penjabi, persa, tailandés, urdu, turco, iraní, esloveno, nepalí, entre otros.

${ }^{8}$ La Ley de Migración contempla entre sus títulos: De la protección a los migrantes que transitan por el territorio nacional; De la presentación de los extranjeros (en estaciones migratorias); De los derechos de los alojados en las estaciones migratorias; Del retorno asistido y la deportación de extranjeros que se encuentren irregularmente en territorio nacional; Del procedimiento administrativo migratorio en materia de regulación migratoria (Ley de Migración, 2011).

128 PRIMER SEMESTRE 2015 
acogerse a la alternativa de la regularización migratoria; la expedición y el otorgamiento de oficio de salida para su egreso del país; y «en teoría» una atención especial en las estaciones migratorias del INM, como servicios de traducción, información y en ocasiones de alimentación especial.

Sin embargo, se trata de medidas intermedias y poco monitoreadas dirigidas a una población migrante que se encuentra en un estado de alta vulnerabilidad debido al poco manejo del idioma, códigos culturales distintos, con grado alto de desgaste emocional, y que ha transitado por más de un continente utilizando redes de tráfico e incluso de trata de personas.

\section{A MANERA DE CIERRE}

Los gobiernos de los países de la región enfrentan dificultades comunes en cuanto al fenómeno de la migración extracontinental, entre ellas, el establecimiento de mecanismos de recepción que sirvan para determinar la identidad, los perfiles y por ende el tipo de protección o tratamiento para cada migrante; para llevar a cabo el proceso de deportación; para implementar mecanismos de cooperación y coordinación internacional que permitan trasladar al migrante al país de tránsito anterior; para contactar a las autoridades consulares de los países de origen. Por ello, es necesario impulsar desde la investigación aplicada iniciativas que permitan profundizar en el conocimiento de estos flujos y en consecuencia diseñar políticas migratorias ad hoc.

Hasta el momento, en el marco de la Conferencia Regional de Migración (CRM) se han trabajado algunas propuestas y acciones encaminadas a fortalecer el diálogo entre países que comparten esta problemática; se constituyó, por ejemplo, el grupo de trabajo ad hoc para discutir, analizar y definir los objetivos que debe seguir la CRM, sumando esfuerzos con la Conferencia Sudamericana de Migración (CSM), en el ánimo de la atención de estos flujos.

Resultado de ello, destacan recomendaciones orientadas a la facilitación, protección y asistencia en el retorno de los migrantes irregulares procedentes de Asia y África, así como para mejorar los sistemas de información que apoyen en la notificación rápida entre los ministerios de migración de la 
región y atención a refugiados; y otras, como generar un registro de abusos y violaciones a migrantes, con el fin de identificar patrones y posibles redes delictivas; promover la cooperación entre los organismos internacionales vinculados con los temas de migración y asilo.

Para atender los desafíos que plantea la migración extracontinental en tránsito irregular por la región e impulsar la integración a la sociedad para aquellos solicitantes de refugio, en términos de cooperación internacional, se ha propuesto homologar en los países de la región el requisito de solicitud de visa a personas procedentes de Asia y África, para desincentivar a los traficantes que usan ciertos países como plataforma o trampolín para internarse en territorio del continente americano.

En México se llevó a cabo en 2012 una reunión de diálogo entre los países miembros de la CRM y algunos países de origen de migrantes extracontinentales, cuyo propósito fue promover el acercamiento entre regiones de origen, tránsito y destino, con el fin de identificar y analizar los desafíos y sus vías de resolución por parte de los países miembros de la CRM o de los países de África y Asia.

\section{CUADRO 2}

Acciones en materia de diálogo internacional para el tratamiento de la migración irregular extracontinental en la región de América Latina

\begin{tabular}{ll}
\hline \multicolumn{1}{c}{ SEDE Y FECHA } & \multicolumn{1}{c}{ ACCIONES } \\
\hline El Salvador, 2003 & $\begin{array}{l}\text { Taller para el retorno digno, seguro y ordenado de migrantes regionales y extra- } \\
\text { rregionales } \\
\text { Costa Rica, 2009 }\end{array}$ \\
$\begin{array}{l}\text { Conferencia regional sobre protección de refugiados y de flujos migratorios mixtos } \\
\text { XV Reunión de la Conferencia Regional sobre Migración }\end{array}$ \\
Ecuador, 2011 & $\begin{array}{l}\text { Conferencia Sudamericana sobre Migraciones (CSM). Presidencia Pro-Témpore } \\
\text { (en diversos años) e intercambio sobre migración extracontinental }\end{array}$ \\
Costa Rica, 2011 & $\begin{array}{l}\text { Diagnóstico sobre la situación actual, tendencias y necesidades de protección y } \\
\text { asistencia de las personas migrantes y refugiadas extra-continentales en México } \\
\text { y América Central }\end{array}$ \\
México, 2012 & $\begin{array}{l}\text { Reunión de diálogo entre los países miembros de la CRM y algunos países de ori- } \\
\text { gen de flujos migratorios irregulares extracontinentales }\end{array}$ \\
\hline
\end{tabular}

Fuente: Elaboración propia con base en expedientes de la Conferencia Regional sobre Migraciones y otros documentos en línea http://www.crmsv.org/

$130 \frac{\text { PRIMER SEMESTRE } 2015}{\text { MIGRACIÓN Y DESARROLLO NÚM. } 24}$ 
Si bien México no es la primera opción como país de destino para los flujos de migrantes irregulares procedentes de Asia y África, en el contexto actual de endurecimiento de fronteras en el norte (Estados Unidos) y fuertes restricciones para el tránsito en el interior del país - derivadas de la violencia y otros factores - podrían ser variables de influencia e impacto en el rumbo de estas migraciones internacionales.

Para poder apuntar a conclusiones sobre el futuro de estos flujos migratorios, hay que considerar que los esfuerzos orquestados desde los organismos internacionales, la academia y el sector gubernamental son incipientes; se cuenta con poca información sobre el destino inmediato de población migrante de origen extracontinental en México.

Saber żqué pasa con aquellos que se regularizan?, o i̇cuáles son sus dinámicas y estrategias de inserción social a la sociedad mexicana?, e incluso, żcuál es su percepción o su cálculo costo-beneficio sobre su situación de irregularidad en México?, son preguntas aún por responder.

La migración de tránsito irregular por México es parte de una agenda cotidiana en los medios de comunicación; la política migratoria en cambio no es tema de todos los días, vive debajo del iceberg. El Estado mexicano concibe actualmente el fenómeno migratorio como un hecho observable de manera integral y transversal, sin embargo, alcanzar esto desde la política pública va más allá del discurso, es necesario llevar a cabo diagnósticos e investigaciones de corte cualitativo y cuantitativo, analizando los flujos migratorios, no sólo eventos descriptivos del México actual, sino del México migrante del futuro.

\section{Bibliografía}

CASILLAS, Rodolfo (2008), Una vida discreta y fugaz. Los centroamericanos transmigrantes en México, México, Comisión Nacional de Derechos Humanos, Organización Internacional para las Migraciones.

Facultad Latinoamericana de Ciencias Sociales (Flacso) (2011), Diagnóstico sobre la situación actual, tendencias y necesidades de protección y asistencia de las personas 
migrantes y refugiadas extracontinentales en México y América Central, Costa Rica, Facultad Latinoamericana de Ciencias Sociales, Organización Internacional para las Migraciones, Alto Comisionado de las Naciones Unidas para los Refugiados. Organización de los Estados Americanos (2010), Migración extracontinental en las Américas, Washington, Comisión Especial de Asuntos Migratorios de la Organización de los Estados Americanos.

Rodríguez, Ernesto (2010), Extranjeros en México. Continuidades y nuevas aproximaciones, México, Centro de Estudios Migratorios del Instituto Nacional de Migración.

Rodríguez, Ernesto, Salvador Berumen y Luis Felipe Ramos (2010), «Migración centroamericana de tránsito irregular por México. Estimaciones y características generales», Apuntes sobre Migración, núm.1, México, Centro de Estudios Migratorios del Instituto Nacional de Migración.

Rodríguez, Ernesto, Luz María Salazar y Graciela Martínez (2012), Construyendo estadísticas. Movilidad y migración internacional, México, Centro de Estudios Migratorios de la Unidad de Política Migratoria, Tilde Editores.

Scott, Sam (2010), UK food businesses' reliance on low-wage migrant labour: a case of choice or constraint?, Oxford University Press, Oxford. 